\title{
Women's experiences of maternal and child health and family planning services in KwaZulu-Natal
}

\author{
S Gatsinzi, MA \\ School of Development Studies, University of KwaZulu Natal, Durban \\ P Maharaj, PhD \\ School of Development Studies, University of KwaZulu Natal, Durban
}

Key words:

Maternal and Child Health, Health

Services, Women's Experiences

\section{Correspondence address:}

Dr Pranitha Maharaj

School of Development Studies

University of KwaZulu-Natal

Durban, South Africa, 4041

Tel : (031) 260-2243

Fax : (031) 260-2359

E-mail : Maharajp7@ukzn.ac.za

\section{Abstract: Curationis 31(2): 14-21}

The increasing recognition that millions of women and children die every year as a result of the poor health of the mother coupled with inadequate care before, during, and after delivery, has highlighted the importance of seeking women's views of health services in order to contribute to improving their health. The purpose of this paper is to shed more light on women's views of health services by exploring their experiences of maternal and child health and family planning services in Cato Manor in KwaZuluNatal. The findings suggest that the majority of women were unclear about the purpose of antenatal care. Most women had little or no knowledge about the required number of antenatal care visits. In addition, few women reported that they were offered a comprehensive range of contraceptive services during their visit. In most cases, they were only given information on a limited number of family planning methods. However, the majority of women expressed overall satisfaction with the services. Discontent mainly rose from the long waiting period, duration of the consultation and limited contraceptive counselling. In order to ensure sustainable improvements in women's health increasing involvement of men is also important.

\section{Introduction}

For women of reproductive age, pregnancy and childbirth are the leading causes of death, disease and disability, accounting for at least $18 \%$ of the global burden of disease in this age group (WHO, 1998:1-3). Every year over four million babies less than one month of age die, most of them during the critical first week of life (WHO, 2003:4). Most of these deaths are a consequence of the poor health and nutritional status of the mother coupled with inadequate antenatal care. There are significant social and economic benefits which are accrued when women stay healthy through accessing antenatal care and family planning (FP) (WHO, 1998:1-3). The use of contraception has health benefits for the women and infant. Contraception is used to prevent unplanned pregnancies, closely spaced pregnancies or pregnancies among women who are very young. The use of contraception may also avert significant economic, social and psychological costs associated with a mistimed or unwanted pregnancy (UNFPA, 2004:5). Providers of contraceptive services may also advise clients to use condoms, which reduce the transmission of sexually transmitted infections (STIs), including HIV/AIDS. This, in turn, can lead to improved pregnancy and delivery outcomes for women, and improved outcomes for their newborns.

Delaying motherhood through the use 
of contraceptive services is likely to have a number of positive outcomes for women. Qualitative research in different countries shows that contraceptive use reduces stress about the risk of unplanned pregnancies and improves relationships between partners (UNFPA, 2004:23). For example, in Bolivia, women using contraceptives demonstrate greater self-esteem than nonusers, and in the Philippines, contraceptive users report greater overall satisfaction with their lives than nonusers (UNFPA, 2004:23). Moreover, the dynamics of smaller families may reduce gender discrimination over the longer term (UNFPA, 2004:24). For example, a study in Ghana found that children, particularly girls in larger families were less likely to attend school and experienced greater inequality within the household than those with fewer siblings (UNFPA, 2004:24). By contributing to smaller families, contraception may contribute to female education and equality. Maternal health care and contraceptive services also provide opportunities to screen women for gender based violence and also, offer opportunities for counselling. Additionally, by protecting and improving health, contraceptive services and maternal health services, like other health interventions, increase productivity in the home and labour force, resulting in personal, household and societal benefits (UNFPA, 2004: 5-25).

Maternal and child health (MCH) services also offer a range of benefits. Studies have shown that a third of every pregnant woman experiences some illnesses during pregnancy (WHO, 2005:6). If not treated properly, these illnesses are likely to result in adverse birth outcomes. Lack of antenatal care has been identified as one of the main causes of pregnancy related deaths and illnesses (Bloom, Shelah, Wypij \& Gupta, 2001:77). Lack of antenatal care can be defined as late initial attendance, few visits, incomplete care, or poor content of care (Gissler and Hemminki, 1994:10). Care during the antenatal period improves a range of health outcomes for women and children (WHO, 2003:13). When women present for antenatal care early in pregnancy, it allows enough time for essential diagnosis and treatment regimens. The antenatal period also acts as an entry point for HIV prevention and care particularly transmission from mother to child. There also appears to be a strong association between the use of antenatal care and delivery assisted by a professional health care provider (WHO, 2003:26). Finally, providers of $\mathrm{MCH}$ services can offer contraceptive counselling, which can help couples space and limit their births and avoid recourse to abortion (UNFPA, 2004:20).

In South Africa, there has been a firm commitment to provide $\mathrm{MCH}$ and FP services as part of a comprehensive reproductive health package. In 1995, the Maternal, Child and Women's Health Policy was drafted to promote and protect the health of mothers, children and women. The specific health objectives were to ensure access to high quality antenatal care and quality care during and after delivery for mothers and their babies. The policy aimed at enabling each child to reach his/her maximum potential within the resources available and enabling as many children as possible to reach adulthood with their potential uncompromised by illness, disability, environmental hazard or unhealthy lifestyle (Department of Health, 1995). The policy stipulates that health education and services should enable the reduction of unwanted pregnancies, offer access to acceptable methods of fertility regulation, and decrease mortality and morbidity from unsafe abortions. However, despite these policy advances in the area of reproductive health, South African women continue to experience high rates of teenage and unintended pregnancies (Cooper, Morroni, Orner, Moodley, Harries, Cullingworth \& Hoffman, 2004:74).

\section{Aim of the Study}

The aim of this research is to shed light on women's views of health services. Specifically, the study explores women's experiences of $\mathrm{MCH}$ and FP services in Cato Manor in KwaZulu-Natal. It largely draws on in-depth interviews with service users. As some of the primary beneficiaries of these services, it is essential to incorporate the views of women service users if sustainable improvements in women's health are to be achieved.

\section{The Context}

This study was conducted at a clinic in Cato Manor, KwaZulu-Natal.

Cato Manor is situated in the eThekwini metropolitan area and is seven kilometres from Durban Central Business District. Durban lies on South Africa's eastern seaboard and is the largest metropole in KwaZulu-Natal with a population of approximately 93000 (Cato Manor Development Association, 2000). This is an area that suffered greatly under the apartheid government's policy of forced removal of squatters. This therefore can partly explain the low socio-economic status of the majority of inhabitants. The post-apartheid development undertakings have had to redress these injustices and promote greater empowerment through construction of low cost housing, schools, libraries, community halls, roads and clinics. The clinic, whose clients were interviewed for this study is one of the clinics constructed in the area as part of the post-apartheid development (Cato Manor Development Association, 2000).

\section{Research Design \\ Research Approach}

This study relied on qualitative data drawn from in-depth interviews to obtain information from women seeking FP and $\mathrm{MCH}$ services at the clinic. Qualitative methodologies yield contextual explanations that are essential for a full understanding of client-provider interactions and for designing useroriented and effective programmes (Simmons and Elias, 1994:6). Qualitative methods, using in-depth interviewing approaches, produce contextual or holistic explanations for a smaller number of cases, with an emphasis on the meaning rather than the frequency of social phenomena (Ulin, Robinson \& McNeill, 2002, Brennan, 1992).

\section{Methods of Data Collection}

In total, $10 \mathrm{FP}$ clients and $10 \mathrm{MCH}$ service users were interviewed. Purposive sampling was used to select participants for the study. The sample framing consisted of clients attending FP and MCH services. Clients were approached directly after they had completed their consultation with the health provider/s and asked if they would be willing to participate in the study. Recruitment of clients stopped when the required sample size had been achieved. Each interview lasted approximately 20 minutes. The primary reason for the relatively short duration of the interview was the limited availability of time. Most of the women could not spend a long time being interviewed. However, the participation rate was high and only a few clients refused to participate in the study citing 
time constraints as the primary reason. All but one interview were conducted by an isiZulu speaking researcher. A female researcher was preferred for the study because it was hoped that women service users would feel free to share their experiences. The in-depth interview guide explored the following topics: role of antenatal care, knowledge of immunization, provision of contraceptive services, partner involvement in FP and $\mathrm{MCH}$ and experience with health services and interpersonal relationship with providers. An interview guide was used to ensure that all the topics considered necessary for understanding the experiences of women were covered. The interviews were conducted in April and May 2005.

\section{Trustworthiness}

To establish trustworthiness of the study, Guba's model (Krefting, 1991) was used. This model uses four criteria of trustworthiness for assessing the value of the findings of qualitative research: truth-value, applicability, consistency and neutrality. In applying these criteria to the study the following measures were taken. A detailed description of the methodology was provided to allow others to determine the applicability of the findings. In addition, all the interviews were tape recorded which provided another mechanism for the independent analysis of the data.

\section{Ethical Considerations and Permission}

In order to gain access to the clinic, permission to conduct the research was first obtained from the provincial department of health in KwaZulu-Natal. First, however, ethical approval to conduct the study was obtained from the University of KwaZulu-Natal. Permission was also obtained from the clinic in which the study was conducted. To avoid disruption of clinic activities, the chief nursing sister was informed of the visit before the interviews. All participants were assured that their responses would be kept strictly confidential to protect them from undue physical or psychological harm as a result of participating in the study. Participants were also assured that the study results would be sent to the organisations working in the area in order to contribute to local knowledge and discussion of the issues that would be raised in the interviews. Upon agreement to participate in the study, clients signed consent forms and permission to taperecord the interviews was sought.

\section{Data Analysis}

Interviews with clients were taped and later translated by the research assistant. A considerable amount of time was spent reading the transcripts and developing themes according to the study objectives and items covered in the interview guide. The transcripts were used extensively to illustrate particular findings. Thematic analysis was used for the analysis of the study findings. Hayes (2000:171) asserts that thematic analysis involves identifying particular themes which occur in the material. Themes are recurrent ideas or topics detected in the transcribed interviews. This method is said to be original, and probably the most straightforward method of all the different qualitative techniques (Hayes, 2000:171)

\section{Results}

The results of the study are divided according to particular themes. The first part examines women's experiences of $\mathrm{MCH}$ services and the second part examines women's experiences of FP services.

\section{Awareness of the Role of Antenatal Care}

An important component of $\mathrm{MCH}$ is antenatal care. Some of the essential components of antenatal care involve checking for eclampsia, anaemia, syphilis, responding to observed signs or volunteered problems, providing preventive measures, advising and counselling on nutrition and self care and developing a birth and an emergency plan (Pattinson, 2003:41). The interviews revealed that the majority of women had inadequate knowledge about antenatal care and its role. For the majority of the women, antenatal care was equivalent to the ultrasound. The women referred to antenatal care as the day for the ultrasound.

Some of the roles of ultrasound include checking the accurate date of the foetus as well for multiple pregnancies, placental location, unsuspected maternal abnormalities and foetal anomalies (Gold, 1994:240). The majority of the respondents were vague about the purpose of ultrasound. According to respondents, the purpose of the ultrasound was to find out whether the child was growing and if it was still alive. This is illustrated in the following comment by one woman:

'What I know' and understand is that my child is alive, he is sitting well. Those are the things that I need to be given here at the clinic' (MCH client, \#2).

However, some of the respondents were able to elaborate on the importance of antenatal care beyond ultrasound. For them, antenatal care also included blood testing, assessing the health of the mother, counselling on breastfeeding and its importance, abstinence and safer sexual practices as well as options available to women who tested positive for HIV. This is illustrated in the following comment:

'they teach you that if you are pregnant that you should go early to the clinic so that you may have blood tests, check if the child is fine and if the mother is in a healthy state to be able to give birth. And how a child is breastfed, and how important that is, and that we should abstain and practise safe sex' (MCH client, \#4).

\section{Number and Timing of Antenatal Care Visits}

WHO (2003) recommends that women have four routine antenatal care visits. The first visit should be before four months, the second visit should be at six months, the third visit at eight months and the final visit at nine months. The findings revealed that almost all women had no or inadequate knowledge about the required number of antenatal care visits. One of the women claimed that she had first visited the clinic on the sixth month of her pregnancy but had been turned away. She therefore only returned to the clinic in her eighth month of pregnancy, as is demonstrated in the following quote:

'I first came in the sixth month of pregnancy, after two weeks they said they only see those who are eight months pregnant. I went and stayed at home and came back when I was in my eighth month of pregnancy' (MCH client, \# 1).

The women were generally uncertain about the required number of antenatal care visits. Even a fourth time antenatal care service user was unsure whether the number of visits was supposed to be three or five. She reported that she 
obtained most of her information from other clients. It would seem that for some participants other women were a more important source of information about the number of antenatal care visit than health providers.

\section{Knowledge of Immunisation}

Immunisation protects children from infectious diseases and forms an important part of child health. The main components of immunisation and childcare entail immunizing the newborn (for example, giving the child the BCG or Hepatitis $B$ vaccine in the first week of life), advising on routine postnatal and follow up visits, and advising the mother to seek care if the baby shows danger signs such as convulsions, fever, bleeding, difficulty in breathing or not feeding at all (WHO, 2007:2-3).

The interviews revealed that most women had some basic knowledge about the importance of immunisation. They were aware of the importance of immunisation for the health and wellbeing of the child. They were also aware that it protects the child against diseases, as shown in the following comments:

'All I know' is that the child receives this injection so that it does not get Polio and other diseases that could possibly be in a child' (MCH client, \#6).

'Immunisation protects the child from sicknesses. The child is protected from sicknesses like chicken pox and many other diseases' (MCH client, \#10).

However, none of the women were able to identify the specific immunisation packages that were administered to their children apart from mentioning the parts of the body where their children had been injected such as thighs and arms, as is revealed in the following statement by one woman.

'This is my first child. I did not know' that I had to immunise my child. They told me that six weeks have to pass and then I should immunise the child, but unfortunately I came on the seventh neek. I did not know the exact timing. I last immunised at King Edward Hospital, and they said that it is for Polio. At this clinic they gave him two injections on his thigh. I do not know if they w'rote it on the card' (MCH client, \# 8).
Furthermore, none of the women were clear about the exact timing and required number of injections for a particular disease. Some of the women also did not understand what the health providers wrote on their children's cards. Inadequate knowledge of immunization may contribute to increased susceptibility to opportunistic infections.

\section{Contraceptive Methods and their Side Effects}

The availability of a range of methods of contraception has been considered a central element of quality of care because it is likely to influence client satisfaction, contraceptive acceptance and continuation (Koenig, Houssain, Whittaker, 1997:278). Askew, Mensch and Adewuyi (1994:272) point out that a client's ability to make an informed choice is determined by the number of methods discussed with her. The choice of methods of contraception offered to women was fairly limited. The vast majority of women reported that they were only given information on injectable contraceptives. They stated that the health providers informed them that injectable contraceptives were best for them. Some women also explained that they prefer to use injectable contraceptives because they only have to remember to take it once every three months while the oral contraceptive requires daily use and they were afraid that they may forget to take it and as a result, may fall pregnant.

'I use Depo because it lasts long. I use it every three months. If I were to use the pill there is the danger that I will forget to use it. The nurse at the clinic suggested the injection for me and they thought that this was the right one for me' (FP client, \#9).

Women rarely received counselling on a range of contraceptive methods which would allow them to make an informed decision. In most cases, they were only given the injection and informed of the dates on which to return. However, one woman explained that clients are sometimes told about condoms. The study findings seemed to suggest that condoms are only promoted as a method of preventing STI/HIV and not as a method of contraception.

'They usually give me all the information when I ask them but if I do not ask anything, they just give me an injection and tell me when I should come back, it does not even take five minutes' ( $F P$ client, \#10).

'Yes, they sometimes tell you about the use of condoms, as you can see 'Love Life' is outside. They tell you about condoms, and sometimes when you go outside, they give you a packet of condoms' (FP client, \#10).

The provision of complete and accurate counselling has been associated with higher levels of client satisfaction, as well as higher contraceptive prevalence and client retention (Townsend, 1991 cited in Creel, Sass and Yinger, 2002:5). It is crucial that all potential users of a method are counseled on what to expect, and how to act regarding side effects they encounter (Gready, Klugman, Xaba \& Boikayo, 1997:27). In the present study, women were not asked whether they had experienced any problems with the method(s) they were using. The majority of women reported that they did not experience any problems with their contraceptive method. However, on further probing, it became clear that women did indeed experience side effects, as is evident in the following comments.

'Side effects? No, I have not experienced side effects. There have been no changes. However, my periods have changed. Sometimes I get them and sometimes I do not' (FP client, \#4).

'I do not see any problems. All I know' is that I am gaining weight. That is all. With regard to changes in my period, I sometimes see drops of blood. I am not sure if this is normal' (FP client, \# 5).

\section{Experiences of Health Services}

In general, the women expressed overall satisfaction with the services they had received. They felt that they had been offered the services they had come to seek. One of the women was quick to point out that she had experienced bleeding during her pregnancy and had been given appropriate treatment at the health facility which stopped the bleeding. A pregnant woman reported that she was particularly happy because when they conducted the ultrasound, they found that her child's heart was 'beating very well'. Many of the women complimented the services they received at the health facility, as is illustrated in the following comment. 
'At this clinic, I have never experienced anything bad. I have only compliments for the services. I have a child that is premature. I brought my child to the clinic and I had him immunised. I saw the difference in my child and I saw him grow quickly' (MCH client, \#9).

In addition, many women described the providers as friendly and helpful but a few disagreed. They felt that they would have liked to have received more information. Interestingly, many of the women felt that there was not sufficient time to ask questions and some felt that providers did not give them the opportunity to ask questions about issues that they thought were important. In addition, some women wanted to ask questions but were uncomfortable raising the topic.

'It does happen sometimes when you find that some of them [nurses] are not friendly, but most of them are fine. There are those who have short tempers, and if you want to ask a question, you see by their facial expression that, Eish! You cannot ask even if you have a problem, now your problem is how do you ask?' (MCH client, \#4).

For the majority of women, the consultation period was very short often lasting approximately five minutes. It was also pointed out that they are usually only given services for which they came to the health facility. Some of the women felt that the consultation was rushed and they felt that the providers would not welcome any questions. However, some women pointed out that providers are willing to offer information if the women request it. Some of the women interviewed summed up what goes on in the consultation room:

'The time spent in the consultation is very short. You just do what you have to do and then leave. It is up to you if you ask questions, but most of the time, things are rushed' (MCH client, \# 10).

'It does not take long because the nurse just asks you if you are coming for the injection and the date of your injection and then after you tell her the dates she injects you and writes it on the card' (FP client, \#2).

The majority of the women complained about the long waiting time. They often spent two to four hours waiting for their consultation. This appeared to be a major cause of frustration among the women. Waiting time is considered an important factor affecting the acceptability of services (Askew, Mensch and Adewuyi, 1994:272). The clients felt that the long waiting period was a result of the providers being slow and mixing up their cards. The following quotes capture the attitudes of women towards the long waiting period.

'I came here in the morning, but those that were behind me have left. And I have not yet been attended to by the provider' (MCH client, \# 3).

'Most of the time, what I come across is that things are slow, you find that we came here long ago, our cards are not yet read. Those who came after us received attention before us. They often mix the cards' (MCH client, \# 10).

Many women observed that it was important to arrive early in the morning in order to receive attention. They attributed the long waiting period to the time of arrival at the health facility. It is interesting that some of these women expect to wait for long periods of time before they receive any attention.

\section{Partner involvement in $\mathrm{MCH}$ and FP services}

Studies have shown that women's health cannot be improved without the involvement of men (Salway, 1994:44). Hence, this study explored whether male partners are involved in $\mathrm{MCH}$ and FP. Women were asked whether they were accompanied to the health facility by their partners. The interviews revealed that the majority of the women were not accompanied by their partners. The women explained that their partners were working and therefore were not able to accompany them to the clinic. The clinic was usually only open during working hours, so it was not possible for the partners to accompany them. Some of the women also felt that there was no need for them to be accompanied by their partners. They preferred to visit the clinic on their own. Also, sometimes partners were not able to accompany their partners because they were caring for their children at home while the women visited the clinic.

'My partner works at night and comes back in the morning. He has no time to accompany me to the clinic' (MCH client, \#3).
'I usually go on my own because he is working. When I come back, I sometimes find him having washed the dishes, cooked, and done the washing. I have never asked him and he has never thought that he has to accompany me. It is just that I am not used to being accompanied. I do not like it when somebody follows me' (MCH client, \# 5).

A minority of women were accompanied by their partners when they were not working. These women explained that men usually provided them with transportation to the health facility. One of the women stated that her partner accompanied her to the clinic, but he remained seated on the bench outside the consultation room. It was clear that even if the partners did not accompany women to the clinic, they continued to support them. Some of the women stated that their partners provided them with financial and emotional support.

'Sometimes my partner accompanies me if he is not working. He accompanies me and then sits outside on the bench and waits for me until we leave' (MCH client, \#5).

'My partner helps me because he is the one who buys disposable nappies, and gives me money to come here to the clinic' (FP client, \#5).

Women were asked if they would want their partners to accompany them during the next visit to the clinic. Some of the women indicated that they had started to think about the importance of including partners in care seeking. However, some women insisted that they did not feel it was necessary to come to the clinic with their partners.

\section{Conclusion}

It is important to begin this discussion with a cautionary note with regard to the findings of the study because of the sample size. However, a number of lessons can be drawn from this study. The results of this study suggest that knowledge of antenatal care was inadequate. This is echoed by studies in other parts of the country and elsewhere in Africa (Myer \& Harrison, 2003:270; Aboud, Lyamuya, Kristoffersen \& Matre, 2002: 91). In their study in Cape Town, Abrahams, Jewkes and Mvo (2001:243) found that Xhosa speaking women were vague about the purpose of antenatal 
care apart from its role in facilitating access to care during labour. In their study of rural South Africa, Myer and Harrison (2003:270) noted that beyond the procurement of antenatal attendance card, most women in their study appeared to see relatively little direct benefit from antenatal care. In Benin, GrossmannKendal, Filippi, Koninck \& Kanhonou (2001:93-4) also found that the majority of the women had very little or no information about the medical procedures used during pregnancy and birth, the causes of the complications they had or the purpose of the treatment they received. Given their limited knowledge of the role of antenatal care, it is highly unlikely that women will demand all the antenatal care services they are entitled to in order to ensure positive pregnancy outcomes.

The results show that the most commonly promoted method of contraception was injectables, a finding consistent with studies in other areas in South Africa (Gready, Klugman, Xaba \& Boikayo, 1997; Maharaj \& Cleland, 2005). However, the widespread promotion of injectable contraceptive limits clients from making informed choices about their method of family planning. It should also be noted that lack of contraceptive counselling contributes to uncertainty about health risks and benefits of different methods. It is also important that providers address women's concerns about particular methods. The findings reveal a general lack of knowledge of the side effects which suggests that women were not told about them. A multi-country study found that side effects involved headaches, dizziness, weight changes, bleeding irregularities, decreased libido, depression and fatigue, nausea, vomiting and heart palpitations (Hardon, 1997: 71). According to Gready et al. (1997: 27), some side effects are annoying but others can be very serious. Hence, it is crucial that all potential users of a method are counselled on what to expect, and how to react to side effects they may encounter.

Studies show that contraceptive counselling is associated with higher levels of client satisfaction, client retention and contraceptive prevalence (Koenig, Hossain \& Whittaker, 1997:8). The findings of the present study revealed that contraceptive counselling seemed inadequate. Importantly, not all clients reported that they were given information on condoms. This is cause of a great deal of concern given the high levels of HIV infection in KwaZulu-Natal. It is important that health services respond to the contraceptive needs of clients specifically with regard to the prevention of HIV and STIs. When the risk of STI/HIV transmission exists, it is important that health care providers promote dual protection, either through the simultaneous use of condoms with other methods or through the consistent and correct use of condoms alone for both pregnancy prevention and disease prevention. The study found that clients are rarely provided with a comprehensive range of services. Most clients reported that they did not receive additional information or services during their visit to the health facility. However, some women pointed out that providers are willing to provide information if they request it.

Overall, women expressed satisfaction with the services they had received at the health facility. However, the long waiting period appeared to be a major cause of frustration among the women. Fonn, Xaba, Tint, Conco \& Varkey (1998:28) attributes the unnecessarily long waiting times at clinics to poor organization and scheduling of services. It seems imperative to point out that while the long waits may not deter women from seeking long term contraceptive services such as injectables, they may deter them from attending the required antenatal visits especially if they have had no problems with the pregnancies. The other concern was the limited duration of the consultation. Many women complained that the consultation was very short and they did not feel that they could ask any questions. It is possible that because of long waiting time and short consultations, women miss out on the information that would be offered during a normal consultation as well as opportunities for improving their relations with providers which impact on the quality of care.

The involvement of men is crucial for the improvement of women's health (Cooper et al., 2004: 79). Studies show that if men are knowledgeable about reproductive health issues and can communicate about them with their partners, they are more likely to be supportive during pregnancy and may make better healthy decisions (Wegner et al., 1998: 38). They are more likely to ensure that their partner receives emergency obstetric services when needed, rather than delaying use of such care (Wegner et al., 1998:38). Kunene, Beksinska, Zondi, Mthembu, Mullick, Ottolenghi, Kleinschmidt, Adamchak, Jenowitz \& Cuthberson (2004:1) noted that it is increasingly becoming clear that every pregnancy in South Africa faces an element of risk, because men, as partners and decision makers, are not informed about reproductive health issues. Furthermore, Tsui, Wasserheit \& Haaga (1997) noted that with respect to obstetric care, it is often families, and not the woman alone, who makes the decision and in the majority of cases, it is men who control the cash reserves or their permission needs to be obtained for obstetric care seeking. Male involvement has the potential of improving women and child health. The present study found that men rarely accompany their partners to health facilities. This does not necessarily mean that they do not support their partners. On the contrary, some of the women reported that their partners provided both emotional and financial support. However, there are numerous challenges to encouraging active participation of men in protecting the health of women and children.

\section{Recommendations}

There should be more emphasis on training to improve the communication skills of the providers to enable them to become a valuable and trusted source of information. As suggested by Huntington and Schuler (1993:191), in some instances, service providers themselves can pose as clients at clinics where they are unknown. The direct experience of the client role could be a useful first step in strengthening empathy and communication skills among clinic staff. This element could be built into preand in-service training programs. This recommendation is also relevant to the study area.

Health facilities have to consider ways of decreasing client waiting time. This may also involve serving regular FP users who are seeking answers to quick questions separately from those having their initial visits. The long waiting time should also be used as a medium for reinforcing oral and visual educational messages especially for new users of the clinic or to deliver specific follow up methods for FP clients who are still in the early method adoption process. 
78.

The dominance of injectable contraceptives limits clients from making informed choices about their method of FP. This inevitably calls for information on other contraceptive methods to help clients have wider choices. It is important that health services respond to the contraceptive needs of clients specifically with regard to sexuality and prevention of HIV and STIs.

Male involvement in different aspects of reproductive health is essential if women's health is to improve. Suggestions for increasing male involvement included use of multimedia messages to inform men and their partners about the importance of male involvement in MCH and FP. Men should be encouraged to accompany their partners to the health facility so that the management of side effects of contraception, the role of antenatal and postpartum care can also be explained to them. Health care workers could also assist in the formation of men's clubs in the communities for the discussion of various issues related to reproductive and sexual health. Kamal (2000:50) found that in southern India more than 25,000 barbers have been trained as community health workers because village men say they feel more comfortable talking to their barbers than to clinic workers.

\section{Reference}

ABOUD, S; LYAMUYA, EF; KRISTOFFERSEN, EK \& MATRE, $R$ 2002: Tetanus Immunity among Pregnant Women Attending Antenatal Care in Dar es Salaam, Tanzania. African Journal of Reproductive Health 6(2):8793.

ABRAHAMS, N; JEWKES, R \& MVO, Z 2001: Health Care-Seeking Practices of Pregnant Women and the Role of the Midwife in Cape Town, South Africa. Journal of Midwiferv \& Women's Health 46(4): 240-247.

ASKEW,I; MENSCH,B \&ADEWUY,A 1994: Indicators for Measuring the Quality of Family Planning Services in Nigeria. Studies in Familv Planning 25(5): 268-283.

BLOOM, S; SHELAH WYPIJ, D \& GUPTA, DM 2001: Dimensions of Women's Autonomy and the Influence of Maternal Health Care Utilization in a North Indian City. Demography. 38(1): 67-
BRENNAN, J 1992: Mixing Methods: Qualitative and Quantitative Research. England, Avebury.

CATO MANOR DEVELOPMENT ASSOCIATION. 2000: Cato Manor Development Project: Status Report 2000. Durban: CMDA.

COOPER, D; MORRONI, C; ORNER, P; MOODLEY, J; HARRIES, J; CULLINGWORTH, L \& HOFFMAN,M 2004: Ten Years of Democracy in South Africa: Documenting Transformation in Reproductive Health Policy and Status.' Reproductive Health Matters 12(24): 70 85.

CREEL, CL; SASS, VJ; YINGER, VN 2002: Client-Centered Quality: Client's Perspectives and Barriers to Receiving Care. Washington: Population Reference Bureau.

DEPARTMENT OF HEALTH. 1995:

Maternal Child and Women's Health Draft Policy Document. Pretoria: Department of Health.

FONN, S; XABA, M; TINT, SK; CONCO, D \& VARKEY, S 1998: Reproductive Health Services in South Africa: From Rhetoric to Implementation. Reproductive Health Matters 6(11): 22 32.

GISSLER, M \& HEMMINKI, E 1994: Amount of antenatal care and infant outcome. European Journal of Obstretrics and Gynecology and Reproductive Biology 56(1): 9-14.

GOLD, RB 1984: Ultrasound Imaging During Pregnancy. Family Planning Perspectives 16(5): 240-243

GREADY,M; KLUGMAN,B; XABA,M \& BOIKAYO, E 1997: South African Women's Experiences of Contraception and Contraceptive Services. In Beyond acceptability: users' perspectives on contraception edited by Ravindran, T.K.S., Berer, M., Cottingham, J. London: Reproductive Health Matters.

GROSSMAN-KENDALL,F; FILIPPI, V; KONINCK, DM \& KANHONOU, L 2001: Giving Birth in Maternity Hospitals in Benin: Testimonies of Women. Reproductive Health Matters 19(18): 90-98.
HARDON, A 1997: Women's views and experiences of hormonal contraceptives: what we know and what we need to find out. In Beyond acceptability: users' perspectives on contraception edited by Ravindran, T.K.S., Berer, M., Cottingham, J. London: Reproductive Health Matters.

HAYES, N 2000: Framework for Qualitative Analysis in Doing Psychological Research. Buckingham: Open University Press.

HUNTINGTON, D \& SCHULER, RS 1993: The Simulated Client Method: Evaluating Client-Provider Interactions in Family Planning Clinics. Studies in Family Planning, 24(3): 187-193.

KAMAL, N. 2000: The influence of husbands on contraceptive use by Bangladesh women. Health Policy and Planning 15(1): 43-51.

KOENIG, M; HOUSSAIN, M \& WHITTAKER, M 1997: The Influence of Quality of Care upon Contraceptive Use in Rural Bangladesh. Studies in Familv Planning 28(4): 278-289.

KREFTING, L1991: Rigor in qualitative research. The assessment of trustworthiness. The American Journal of Occupational Nurses. 45(3): 214-219.

KUNENE, B; BEKSINSKA, M;ZONDI, S; MTHEMBU, N; MULLICK, $\mathrm{S}$; OTTOLENGHI, E; KI EINSCHMIDT,L; ADAMCHAK, S; JENOWITZ, B \& CUTHBERSON, C 2004: Involving Men in Maternity Care, South Africa. Johannesburg: Reproductive Health Research Unit.

MAHARAJ, P \& CLELAND, J 2005: Integration of sexual and reproductive health services in KwaZulu-Natal, South Africa. Health Policy and Planning 20(5): 310-318.

MYER, L \& HARRISON, A 2003: Why Do Women Seek Antenatal Care Late? Perspectives from Rural South Africa. Joumal of Midwiferv \& Women's Health 48(4): 268-272.

PATTINSON, RC 2003: Saving Babies 2002: Third Perinatal Care Survey of South Africa. Pretoria: Department of Health.

SALWAY, S 1994: How Attitudes Toward Family Planning and Discussion 
Between Wives and Husbands Affect Contraceptive Use in Ghana. International Family Planning Perspectives 20 (2): 44-47.

SIMMONS, R \& ELIAS, C 1994: The Study of Client-Provider Interactions: A Review of Methodological Issues. Studies in Family Planning 25(1): 1-17.

SOUTH AFRICAN DEMOGRAPHIC AND HEALTH SURVEY. (SADHS) 1999: South African Demographic and Health Survey 1998: Full Report. Pretoria and Calverton: South African Medical Research Council and Macro International.

STATISTICS SOUTHAFRICA. 2004: Census in Brief: The People of South Africa Population Census 2001. Pretoria: Statistics South Africa.

TSUI, AO; WASSERHEIT, JN \& HAAGA, J 1997: Reproductive Health in Developing Countries: Expanding Dimensions, Building Solutions. Panel on Reproductive Health, National Research Council. Washington, DC: National Academy of Sciences.

ULIN, RP; ROBINSON, TE \& MCNEILL, TE 2002: Qualitative Methods: A field Guide for Applied Research in Sexual and Reproductive Health. North Carolina, USA: Family Health International.

UNFPA. 2004: Adding It Up, The Benefits of Investing in Sexual and Reproductive Health Care. New York: UNFPA.

WEGNER, NM; LANDRY, E; WILKINSON, D \& TZANIS, J 1998: Men as Partners in Reproductive Health: From Issues to Action. International Familv Planning Perspectives 24(1): 38 42.

WHO. 1998: World Health Day: Safe Motherhood As a Vital Social and Economic Investment. Geneva: WHO.

WHO. 2003: Pregnancy, Childbirth, Postpartum and Newborn Care: A guide for essential practice. Geneva: WHO.

WHO. 2004: Beyond the Numbers: Reviewing maternal deaths and complications to make pregnancy safer. Geneva: WHO.
WHO. 2005: Selected practice recommendations for contraceptive use. Geneva: WHO.

WHO. 2007: WHO Recommended Interventions for Improving Maternal and Newborn Health. Geneva: WHO. 